other classes, give significantly higher scores on tests of 'level of aspiration' and of anxiety.

The next speaker, Dr. A. T. M. Wilson, discussed "Social Changes in Structured Groups", a group being termed structured when it contains a manifest system of inter-related roles. The study of social processes in real (that is, not artificially created) situations, in terms of the psychological and social forces concerned, raises problems connected with the possibility of obtaining access to the group for the purpose of direct observation. There may be resistance or reluctance to proposals that the social investigator should be admitted to a 'reality situation', and this raises questions concerning the role of a participant observer in a community particularly susceptible to social change. If in a structured group need is felt for help in bringing about desired change, this need will provide one set of circumstances facilitating access by the investigator. A research worker, responding to a request for technical collaboration, in tackling a group problem, may assume a role the existence and independence of which are derived from its responsible professional character. The use of such roles may facilitate social change, since insight, derived from observations equally available to the group concerned and to the research worker, can be mutually communicated. The scope and limitations of such an approach were illustrated in detail from the work of one industrial organization. which employs it.

Prof. T. H. Pear discussed "The Social Psychology of Everyday Life". This paper's title, borrowed with grateful acknowledgment, is that of a well-known article by Prof. Hadley Cantril, of Princeton University ${ }^{1}$. Written seventeen years ago, it urged that really important events in the lives of ordinary people had seldom been studied by psychologists.

To-day, one can report a considerable increase in the social significance of the subjects studied. The development of techniques for investigating attitudes and public opinion and for interviewing (for example, in vocational guidance, medicine and anthropology), the study of likenesses and differences in national characteristics and the effect of social factors upon test performances, the intensive study of patterns of culture and tensions between communities ${ }^{2}$, all these events and more testify to a considerable change in the climate of opinion. The ordinary man in his social setting here and now is gradually if slowly becoming an object of scientific interest.

There are still important subjects which have received relatively little attention from social psychologists. Of these the most obvious are peace and war, since to-day almost all problems of planning are affected by the possibility of another war. Another neglected subject in Britain is social stratification. To the study of these subjects there certainly exist strong resistances; to discover and account for them is an interesting task for the social psychology of the future.

Prof. Pear's paper suggested that discovering the causes of this oversight is an interesting psychological project. Consider differences in classes, strata and élites. Much has been written about inferiority complexes ${ }^{3}$, and our knowledge in this realm would be enriched by introspective accounts of how it feels to find oneself in such 'natural' situations of superiority or inferiority, and of the modifications of behaviour which one deliberately produces to adjust oneself. Partly conscious, partly unconscious factors may cause the widespread lack of interest among psychologists in problems of peace and war and of social stratification. It is time to realize frankly that in many people there are conscious reasons for not objecting to war. Unconscious reasons exist too; but they have had a good Press for the past three decades, and more research into the conscious reasons is needed. It is time for students of society to direct public attention less to the differences between peoples and much more to their resemblances, even if this decreases the 'noveltyrarity' value of their books and lectures.

During the meeting a demonstration was given of a film-gramophone technique, devised by Davide Boulting, C. E. M. Hansel and Prof. Pear, to investigate impressions of personality, vocation and social stratum from voice and facial appearance. While a voice spoke a prescribed passage designed to bring out geographical or social 'accents', pictured 'back. grounds', both physical and social, and faces were projected on the screen. In the experiments to be carried out, subjects will attempt to match these with the voices.

1 Psychol. Bull., 297 (1934).

2 cf. Klineberg, Otto, "Tensions Affecting International Understanding", Bull. 62, Social Science Research Council, New York, $17(1950)$.

${ }^{3}$ cf. Brachfleld, Oliver, "Inferiority Feelings" (London: Routledge and Kegan Paul, 1951).

\section{RECENT DEVELOPMENTS AND TECHNIQUES IN THE MAINTENANCE OF STANDARDS}

AWO-DAY symposium was held at the National Physical Laboratory during May 21 and 22 on "Recent Developments and Techniques in the Maintenance of Standards". Most of the standardizing laboratories of Europe, the Commonwealth and North America were represented, and delegates attended frorn many research organizations and industrial firms in Great Britain. Dr. E. C. Bullard, director of the Laboratory, in opening the symposium, remarked that it had every chance of being a successful occasion since there was no official business of any kind and no one need come to any conclusions. Sir Ben Lockspeiser, secretary of the Department of Scientific and Industrial Iiesearch, was among the audience and added his welcome to Dr. Bullard's.

Dr. D. G. Sopwith, superintendent of the Engineering Division of the Laboratory, took the chair for the first session, on "Primary Load Standards". The first paper was presented by Mr. B. L. Wilson, head of the Engineering Mechanics Section of the National Bureau of Standards, Washington. He gave a very interesting summary of the various dead-weight machines belonging to the Bureau and the types of devices calibrated in them. Dr. F. Aughtio (National Physical Laboratory) followed this with a paper on "The Primary Load Standard" in which he described the 50-ton dead-weight standard at the National Physical Laboratory and spoke of the adjustment of it to 'standard' gravity $(980.665 \mathrm{~cm}$./sec.), which was about to be undertaken. He described also the Laboratory's 5-ton standard for the calibration of small proving rings, and experiments with resistancestrain gauges on compression elements for loads greater than 50 tons.

The second session was concerned with "The Standard of Length", and Mr. F. H. Rolt, super- 
intendent of the Metrology Division, National Physical Laboratory, was chairman. The first paper, "The Present State of a Lightwave Standard of Length", by Dr. E. Engelhard (PhysikalischTechnische Bundesanstalt, Brunswick), was presented for him by Mr. H. Barrell (National Physical Laboratory) in the form of a summary. It was pointed out that for more than twenty years, industrial end-gauges have been calibrated by reference to wave-lengths of light, and at the same time investigations have continued to find the best light sources. The pure mercury isotope ${ }_{80}^{198} \mathrm{Hg}$ and the krypton isotopes ${ }_{36}^{84} \mathrm{Kr}$ and ${ }_{36}^{86} \mathrm{Kr}$ are now available for the excitation of an optical wave-length standard of great accuracy.

The method developed by Kösters at the Physikalisch-Technische Reichsanstalt (now the Physikalisch-Technische Bundesanstalt) for comparing wave-lengths of light with the metre has some interesting features, first in the use of a new type of beam divider, the 'interference double prism', secondly in the direct absolute interferometric measurement of an industrial 500-mm. end-gauge by means of Fizeau's fringes and the subsequent direct comparison of the end-gauge with an Endstrichmeter (a line metre which is also an end-gauge), and thirdly in the elimination of the refraction of air by means of a vacuum chamber.

The question whether a light-wave standard ought to be defined by wave-length in air or in vacuo was discussed. Kösters's method of eliminating the refraction of air removes the objection to a vacuum wave-length standard that in practice all measurements (for example, of block gauges) would be made in air.

The relative advantages of the mercury isotope and the krypton isotopes as sources of light were discussed, and the use of the krypton lamps at the temperature of freezing nitrogen was described. Experiments using xenon instead of krypton have so far not met with success. Various manifestations of line broadening and line displacement were discussed, and the essential conditions were specified for eliminating self-reversal and asymmetry of lines, which would lead to errors in the use of a light-wave standard.

It is not possible at present to realize an ideal light-wave standard. Lines emitted by an atomic beam would be ideal theoretically, but the intensity is too low. The question now is whether a mercury or a krypton isotope should be used to define the new standard of length.

Mr. Barrell then read his own paper, "The Interferometry of Length", in which he began by summarizing the history of the spectroseopic reference standard, the red line of cadmium, with the events leading to the present use of the mercury isotope ${ }_{80}^{198} \mathrm{Hg}$ and the krypton isotopes ${ }_{36}^{84} \mathrm{Kr}$ and ${ }_{36}^{86} \mathrm{Kr}$. $\mathrm{He}$ reviewed the progress of the investigations to select a wave-length to serve as the ultimate standard of length.

For the mercury isotopes, a simple form of electrodeless discharge lamp, free from certain broadening effects, has been designed at the National Bureau of Standards, Washington, by Meggers and Westfall. A series of well-distributed wave-length standards reproducible to $\pm 0 \cdot 0001 \mathrm{~A}$. has been provided from the isotope ${ }_{80}^{198} \mathrm{Hg}$; these standards have recently been used at the National Physical Laboratory for testing the accuracy of a new dispersion equation for air, valid over the range $2500-6500 \mathrm{~A}$.
In Great Britain, various types of mercury-198 discharge lamps are now being produced commercially by the General Electric Company, Ltd. At present, the electrodeless lamp with $3 \mathrm{~mm}$. argon is the best source of mercury-198 standards, but it has been established at the National Physical Laboratory that the argon produces slight asymmetrical broadening of the mercury-198 lines, the consequent red shift in the visible spectrum amounting to $0.0001 \mathrm{~A}$. $\left(-0.0003 \mathrm{~cm}^{-1}\right)$ per mm. of argon. The amount of argon in the lamps must therefore be controlled with $0.5 \mathrm{~mm}$. mercury pressure to ensure reproducibility of wave-length within 1 part in $10^{8}$.

The direct measurement of length by interferometry is now generally applied whenever the utmost precision and reliability are required. A specially designed form of Fizeau interferometer at the National Physical Laboratory will accept for measurement at one time up to twenty block gauges of size $2 \cdot 5 \mathrm{~cm}$. or less.

At the National Physical Laboratory, experiments in the measurement of distances of several metres are being made with electromagnetic waves of radio-frequency, using an interferometer of a modified Michelson form; a stabilized klystron source generates microwaves of frequency 24,000 Mc./s. $(=1.25 \mathrm{~cm}$.). The velocity of radio waves may be determined by reversing the process employed.

In answer to a question as to whether the refractive index of air was known to the accuracy demanded for interferometric work, Mr. Barrell said that wavelength measurements made in air can now be reduced to the vacuum condition (or vice versa) with a reliability of 3 parts in $10^{8}$.

For the afternoon session, on "Standards of Radioactive Isotopes", Dr. B. W. Robinson, superintendent of the Physics Division, National Physical Laboratory, took the chair, and Mr. R. C. Hawkings (Atomic Energy Project, National Research Council of Canada, Chalk River, Ontario) read the first paper, prepared by himself, W. F. Merritt and J. H. Craven, on "The Maintenance of Radioactive Standards with a $4 \pi$ Proportional Counter".

There is a need for instruments by which the absolute rates of disintegration of atoms can be directly measured, and there are many advantages in a particle counter having a solid angle of 4 steradians with the source. The workers at Chalk River have constructed a spherical $4 \pi$ counter, which Mr. Hawkings described in detail. Each of the two sections consists of a hemispherical brass cathode having an anode connexion passing through a plastic insulator in the apex. The operation of the counter was described, with the type of amplifier made necessary by the wide distribution of pulse heights originating in it. The type of plateau obtained and the linearity up to $3 \times 10^{4}$ counts per second are very satisfactory.

The efficiency of the $4 \pi$ counter is reduced to some extent by absorption losses in the source mount and self-absorption of the source itself. The losses in the mount, however, can be minimized by using the thinnest possible film; the correction is determined by placing an identical film over the source and then applying the reduction in count as a correction to the original count. Film-absorption correction factors for some commonly used nuclides were listed. The elimination of self-absorption losses was also discussed.

The relative regions of maximum efficiency using various counter gases were discussed, and the stability and reproducibility of the counter. The limiting factor 
in attempts to increase accuracy now seems to be the technique of preparation of the source. Results obtained with the counter were compared with those derived from other methods, for example, defined solid angle and coincidence, for various nuclides.

The counter described, while sturdy and easily and quickly decontaminated and reassembled, is nevertheless a precision instrument which, when used in conjunction with the coincidence method of counting, has already proved invaluable in Canada and the United States.

The second paper of this session, by Mr. W. E. Perry (National Physical Laboratory), dealt with "Standardization of Radioactive Isotopes by Coincidence and $\gamma$-Ray Ionization Methods". Pure specimens of artificial radioactive isotopes in weighable quantities are not available; hence it has not been possible to prepare gravimetric standards as with radium. Standardization therefore requires activity measurements. At the National Physical Laboratory three methods have been used : $\beta$-particle counting by the small defined solid-angle method, the $(\beta-\gamma)$ coincidence method and the $\gamma$-ray ionization method. Mr. Perry's paper was concerned with the last two.

In the $(\beta-\gamma)$ coincidence method, the elementary formula for the disintegration-rate was derived, and the modifications to it to allow for various types of unwanted coincidences were discussed. The method requires two separate counting measurements and the measurement of the resolving time of the coincidence circuit, and the techniques of these were described. In particular, the introduction of an absorption screen, used to separate $\beta$ - from $\gamma$-counts, is open to argument.

Results of the measurements of six cobalt-60 sources were given, in which the accumulated total error is thought to be at least \pm 2 per cent.

The $\gamma$-ray ionization method was also briefly described. This is based on the relationship between ionization and the $\gamma$-ray energy : a value may be derived for the ionization produced by $\gamma$-rays from a given quantity of a radioactive isotope if certain fundamental constants can be assumed. Results were given of comparative measurements using both the coincidence method and the ionization method; the uncertainty in the ionization values is believed to be about \pm 4 per cent and the differences between the ionization and coincidence values do not exceed this. Activity values for isotopes reported by various institutions in Great Britain reveal differences of the same size, and investigation must continue so that reliable standards may be provided and maintained.

After the two papers, Prof. J. Rotblat (St. Bartholomew's Hospital Medical College, London) opened a lively discussion on the method described by Mr. Hawkings of evaluating the correction for absorption in the source mount and on the effects of backscatter on the correction. There was some discussion also on the relative accuracy of the various counting methods; Mr. Hawkings considered that a great drawback of the coincidence method is the complexity of the electronic apparatus, which permits errors to arise.

Dr. Robinson was also in the chair for the first session on the following morning, when the subject was "Temperature". Dr. H. van Dijk (Kamerlingh Onnes Laboratory, University of Leyden) read a paper on "The Extension of the International Tem. perature Scale below the Oxygen Point", in which he summarized and discussed the most recent measurements of the thermodynamic temperature of the boiling point of hydrogen and helium, with the possibilities for interpolation between these fixed points and for extension of the scale below $4 \cdot 2^{\circ} \mathrm{K}$.

This was followed by a paper by Mr. C. R. Barber (National Physical Laboratory) on "Improvements in the Realization of the International Temperature Scale over the range $-182 \cdot 97^{\circ}$ C. to $630 \cdot 5^{\circ}$ C.", an account of work in progress at the National Physical Laboratory. A platinum resistance thermometer and Smith bridge of new design were described; the noteworthy feature of the bridge is the form of the coils, which are specially wound to give freedom from mechanical strain. An account was also given of apparatus of now design for realizing the steam and sulphur points.

Dr. L. A. Sayce, superintendent of the Light Division, National Physical Laboratory, was chairman for the next session, which dealt with "The Standard of Luminance", and Dr. J. W. T. Walsh (National Physical Laboratory) presented the first paper, on "The Establishment of the Photometric Scale at the National Physical Laboratory", in which he described the primary standard of light, the preparation of sub-standards and working standards and the accuracy which can be assigned to the results of measurements made at the Laboratory on lamps submitted for standardization. M. J. Terrien (Bureau International des Poids et Mesures, Sèvres) then read a paper on "Co-ordination of the Photometric Units at the B.I.P.M.", in which he described the arrangements made for comparing the photometric units of the standardizing laboratories of France, Great Britain, United States, U.S.S.R., Germany and Japan, and the equipment of the photometric laboratory at Sèvres. It is estimated that the precision with which the B.I.P.M. comparisons indicates the value of the photometric standards throughout the world is, on an average, three or four parts in a thousand; an important source of error is variation in the lamps during transport.

For the final session, on "Standards of Frequency", the chair was taken by Mr. R. S. J. Spilsbury, superintendent of the Electricity Division, National Physical Laboratory. Dr. Erik Bergstrand (Kart. verket, Stockholm) read a paper on "The Precision of Optical Methods for the Determination of the Velocity of Light", in which he made a critical survey of the methods and results of the main optical experiments and described in detail his own method in 1950 using a Kerr cell. He believes that the new value first obtained at the National Physical Laboratory by the cavity resonator method is not incompatible with the earlier results when these are given more realistic limits of error ; the reason for earlier workers' almost universal arrival at lower values is perhaps that they were unconsciously influenced by the results of the elaborate experiments in 1931 and 1932 with the mile-long evacuated pipe. Dr. L. Essen (National Physical Laboratory) then described, in a paper on "The Measurement of Time, Frequency and Velocity", the recent improvements in the technique of frequency measurement, particularly at microwave frequencies. The measurement of velocity was one application of these techniques and another was likely to be the development of an atomic frequency standard. In the discussion which followed, Mr. J. H. Briggs (Telecommunications Research Establishment), Mr. H. M. Smith (Royal Observatory) and Mr. H. B. Law (Post Office Research Station) all supported the need for an atomic clock, 
but Dr. L. Hartshorn (National Physical Laboratory) raised the question why we believe that atomic standards will be more nearly constant than other material standards. The question can only be answered by the agreement between different experiments and, as Dr. Bullard pointed out, agreement does not always indicate that the answer is correct.

The full proceedings of the symposium are to be published by H.M. Stationery Office in the course of the next few months.

M. M. Postgate

\section{OLD MOUNTAINS OF NEW GUINEA* \\ By L. EVELYN CHEESMAN}

$\mathrm{F}^{\mathrm{o}}$

$\mathrm{R}$ all taxonomists interested in the west Pacific the fact that New Guinea possesses series of pre-Cambrian rock that have never been submerged has significance which cannot be over-stressed. Their existence indicates a solution of what otherwise would be inexplicable, namely, whence New Guinea derived its Oriental insect fauna and flora.

The huge island was raised from a drowned landmass by the Miocene-Pliocene tectonic movements. So much is well known; but this furnishes no working hypothesis for botanists or for entomologists. The deductions which appear self-evident actually conflict with biological data; and, owing to their antiquity, it is to the insects and plants that we must turn for convincing evidence of land movements.

Land raised from the ocean bed during the Tertiary, its only subsequent continental connexion being periodically with Queensland and by sundry land bridges to Asia through the Philippines, might be expected to possess a flora and fauna basically Australian with an Oriental influence. Moreover, they should be discontinuous with many lacunæ in their totality. On the contrary, analyses of species belonging to any important group reveal an undoubted Oriental origin. There is an Australian elementmore or less strong according to the group. There is a Malaysian influence attributable to a common Asiatic ancestry. There is a very rich peculiar neoendemism suggesting isolation over a long period which makes Papuasia, that is, New Guinea with adjacent islands and archipelagoes, an extremely distinct zoological sub-region in geologically recent times. The flora and insect fauna are harmonious, their totalities show no serious lacunæ and no important group is unrepresented.

Papuasia therefore ranks with Australia and Asia in its continental full populations and not with neighbouring land-masses, Sumatra, Java and Borneo. These were also raised during the Tertiary, connected for a period with Asia and then isolated; but they possess a discontinuous flora and insect fauna.

Whence then did New Guinea receive its continental populations, since palæogeology apparently does not support the conclusions of botanists and entomologists ?

We find on analysis of species that : (1) the average ratio of the older species groups is one-tenth Australian, three-tenths Asiatic, and six-tenths endemic; (2) the nearest genera allied to Papuasian endemic genera are found in Asia; (3) genera which are represented in both Malaysia and Papuasia are also found in India, Burma or China, often in all three countries.

* Substance of a paper read before the Royal Entomological Society on August 15.
This points to a two-branched migration from the continent, which can be foreseen because there has been no land connexion between Malaysia and New Guinea subsequent to the Late Cretaceous. Otherwise the Sumatra tiger and monkeys and apes would have found their way to the New Guinea forests.

Before the War, Prof. Lam, of Leyden, was engaged on an analysis of the flora of Malaysia and Dutch New Guinea. $\mathrm{He}$ found that the proportionate representation was approximately the same as in the Insecta, and he agreed also with points (1), (2) and (3). Botanists have a decided advantage over entomologists in such matters because their material collected and determined is far more abundant. As in the Insecta there are no very old forms ; the slight South American influence comes through Australia. There are many endemic genera but no endemic family.

The fact that there are two distinct geanticlines in New Guinea belonging to different periods sheds a most important light upon these questions of the distribution of species. The ancient geanticline was investigated by the Australian government geologist, R. C. Stanley, and his results were published in 1923 . $\mathrm{He}$ directed attention to the existence of this ancient wrecked mountain system represented by relics, some of which have never been submerged, pre-Cambrian and Asiatic in origin. They are situated along the northern coast of New Guinea with the same alignment as the young Tertian central ranges which are Malaysian in origin. It is concluded that as the folding movements raised the central ranges the greater part of this old northern system was submerged. The series comprises south-west New Britain, which is still subsiding and has never been submerged, Finisterre Mountains, Torricelli Range, Oinake Massiv (Mount Bougainville), Cyclops Range which has never submerged, Japen Island, and Waigeu Island.

These form the margin of a drowned land which for my present purpose I have named Cyclopea. All these remnants are characterized by a strong tilting on their ocean side so that valley heads and gullies alone remain above the sea, and on their shoreward side there is a proportional elevation with much weathered cliffs of Cretaceous limestone containing Eocene Foraminifera. There has been land subsidence on a huge scale.

If we conceive this lost land-mass Cyclopea as having maintained connexion with Asia until the Early Pliocene, there we have ancient fully populated land from which the young land would be colonized as it rose from the ocean bed. This is acceptable to geologists and accords with the biological evidence. It is, in fact, the only working hypothesis satisfactory for taxonomists. The drift and overthrust of continents in that part of the globe does not directly concern biologists of New Guinea to-day, because Cretaceous New Guinea of yesterday, which with New Zealand formed the margin of Australia, was sub. merged, and the stupendous folding movements entirely altered all previous land formation.

Cyclopea has a different history; but whether palæogeologists decide that the land looped, festooned, arched, buckled, or streamed by New Guinea with the Solomon Islands in pursuit is immaterial to us. What we do insist is that they must postulate Cyclopea as a continuous land to Asia through the Moluccas and the Philippines prior to the Early Pliocene, otherwise any hypothesis will be rejected as untenable because of the testimony of botanists and entomologists. 